\title{
ESTUDOS ORGANIZACIONAIS NO BRASIL: ARRISCANDO PERSPECTIVAS
}

\section{José Henrique de Faria ${ }^{1}$}

\section{Resumo}

O propósito deste artigo é, a partir do que chamo de elementos constitutivos dos Estudos Organizacionais - EOR, arriscar elaborar perspectivas para esta área. Como de hábito, não vou abdicar de eleger categorias (no caso, elementos constitutivos), as quais, naturalmente, encontram-se na realidade e foram apropriadas como concreto pensado.

Palavras-chave: Estudos Organizacionais; Espistemologia; Abordagens Teóricas.

\section{ORGANIZATION STUDIES IN BRAZIL: PERSPECTIVES}

\begin{abstract}
The purpose of this article is, From do que call constitutive elements of organizational studies - EOR, risking develop perspectives for this area . As a smoker, I will not surrender to elect CATEGORIES (no case , constituent elements ), as Which, of course, are -If Reality and Were Apropriadas as concrete thought .
\end{abstract}

Keywords: Organization Studies; Epistemology; Theoretical Approaches.

\footnotetext{
${ }^{1}$ Professor Titular do PPGADM - UFPR. E-mail: jhfaria@gmail.com 


\section{Introdução}

Devo alertar o leitor, desde logo, na linha de Nicos Poulantzas ("O Estado, o poder, o socialismo". Rio de Janeiro: GRAAL, 1981. p. 12), que "assumo a responsabilidade do que escrevo e falo em meu próprio nome". O propósito deste artigo é, a partir do que chamo de elementos constitutivos dos Estudos Organizacionais - EOR, arriscar elaborar perspectivas para esta área. Como de hábito, não vou abdicar de eleger categorias (no caso, elementos constitutivos), as quais, naturalmente, encontram-se na realidade e foram apropriadas como concreto pensado. $\mathrm{O}$ espaço para estas reflexões é restrito, o que me obriga a considerar, ainda tal como Poulantzas (op. cit. p. 11), "que os problemas atuais [dos EOR] são suficientemente importantes e novos para merecerem um tratamento aprofundado".

A publicação na área de estudos organizacionais enquanto tal inicia formalmente, no Brasil, na década de 1950, como se pode constatar em um texto básico no qual Beatriz M. de Souza Wahrlich ("Uma análise das teorias de organização". Rio de Janeiro: EBAPE/FGV, 1958) faz uma análise das principais teorias disponíveis à época seguindo a mesma linha de produção acadêmica americana, representada por Selznick, Simon, Barnard, Mooney, entre outros. Wahrlich questiona, já na época, o fato de que o campo teórico de estudos organizacionais é subestimado em favor de seu "aspecto prático" (ou seja, o gerencialismo). Entretanto, a própria Wahrlich utiliza indistintamente os termos organização e administração ao longo da análise, defendendo a ideia de uma teoria generalizada de organizações a partir da possibilidade de interação entre teorias da administração pública e da administração de empresas privadas.

Estudos sobre organizações na década de 1950, como, por exemplo, os de Guerreiro Ramos ("Uma introdução à história da organização racional do trabalho", de 1952; "Relaciones humanas del trabajo", publicado no México em 1954), ainda não tratavam especificamente da teoria das organizações, mas as tomavam como objeto de análise. Este, talvez, seja o ponto mais importante da história dos estudos organizacionais no Brasil: a organização como objeto de estudo.

Desde então, de maneira bem simplificada, os estudos organizacionais no Brasil apresentaram duas linhas elementares distintas de abordagem: (i) aqueles vinculados ao management, ao business, aos princípios de administração pública e privada; (ii) aqueles vinculados às "ciências humanas e sociais" (sociologia, psicologia, filosofia, ciência política, antropologia, educação, etc.), sejam estes disciplinares (sociologia das organizações, psicologia das organizações), multidisciplinares ou interdisciplinares. Em ambos os casos, as dimensões epistemológicas e metodológicas que atravessam estes estudos são de diferentes matizes: positivismo, funcionalismo, estruturalismo, fenomenologia, materialismo histórico e pragmatismo. 
Mais de meio século após as primeiras publicações na área de estudos organizacionais, não há dúvida que estes ganharam um corpo teórico relativamente autônomo, atingiram um nível importante de representatividade acadêmica, caracterizaram-se com alguma ênfase na multi e na interdisciplinaridade e atualmente apresentam uma forte tendência a se separarem das teorias de business e management. Neste último caso, há um discurso consistente que defende a separação dos estudos organizacionais dos estudos de business, como ficou caracterizado nas diversas intervenções dos participantes do I Colóquio Internacional em Estudos Organizacionais realizado na EAESP-FGV em Agosto de 2013.

Ao mesmo tempo em que a área de EOR ganha certa autonomia, a criação da Sociedade Brasileira de Estudos Organizacionais - SBEO em 2012 se dá por iniciativa de pesquisadores vinculados aos programas de pós-graduação em administração. Ainda que o propósito da SBEO seja congregar as diversas áreas disciplinares, é na área de administração que a mesma se consolida. Este fato exige uma reflexão mais acurada sobre as perspectivas da área que, embora mencione mais adiante, não terei como aprofundar adequadamente.

Uma das propostas do I Congresso Brasileiro de Estudos Organizacionais e que orienta a apresentação dessa Revista, é a de tentar projetar algumas perspectivas para os estudos organizacionais no Brasil. Certamente, as avaliações devem divergir, pois não há como fazê-las sem uma dose de especulação, mas as mesmas são muito oportunas para uma reflexão crítica.

Permito-me sugerir o que entendo serem elementos constitutivos dos estudos organizacionais (que também chamei de categorias analíticas), de forma a orientar minha avaliação sobre suas perspectivas. Os estudos organizacionais devem:

i. Caracterizar-se pela Interdisciplinaridade (com possibilidades para a multidisciplinaridade): o conhecimento sobre a realidade organizacional demanda um diálogo permanente entre diversas disciplinas. Os estudos disciplinares (sociologia das organizações, psicologia organizacional, economia industrial, gestão organizacional, etc.) tendem a abordar aspectos muito particulares do fenômeno, restringindo o entendimento de sua totalidade;

ii. Considerar a organização como objeto de pesquisa em sua materialidade: é preciso superar a tendência à abstração e generalização que tende a extrapolar aspectos de diferentes tipos, formas, contextos históricos e sociais, estruturas e finalidades de organizações para toda e qualquer realidade organizacional;

iii. Superar a xenofobia teórica: em uma época na qual o globalismo apresenta-se como totalização da economia e da 
sociedade, a concepção de estudos organizacionais tipicamente brasileiros é retrógada. Não se trata de incentivar a importação de teorias prontas ou de incorporar teorias sem cuidados, sem críticas e sem rigor. Trata-se de reconhecer que a ciência e seu desenvolvimento não podem ficar confinados a escaninhos particulares, como se isto fosse demonstração inequívoca de autonomia, de independência na produção acadêmica, de não submissão ao imperialismo científico e coisas do gênero. O que é preciso, de todo modo, suplantar, não é o uso inadequado de teorias produzidas fora do Brasil, mas o uso de teorias prontas que são aplicadas ou testadas aqui como se nossa realidade fosse um mero campo de provas;

iv. Sobrepujar a prática dos feudos acadêmicos competitivos: há uma prática, com consequências perversas para o avanço do conhecimento, que consiste em estabelecer grupos de pesquisa que se esmeram em distinguir-se dos demais para efeitos de competição, seja por recursos, seja por "prestígio autoimputado", sem qualquer esforço pela cooperação na produção da pesquisa. As distinções teóricas, metodológicas e epistemológicas são saudáveis e necessárias para a área e não são impeditivas de colaboração e parceria em projetos acadêmicos. Estes grupos, geralmente vinculados a programas de pós-graduação, tendem a sobrevalorizar sua pesquisa em detrimento do avanço do conhecimento do campo $^{2}$.

Não tenho nenhuma ilusão quanto à eficácia e à amplitude destes elementos constitutivos. Eles são apenas uma tentativa de organizar minhas argumentações e não um exaustivo tratamento acadêmico ao tema. Considerando, portanto, estes elementos constitutivos básicos e limitados, é possível alinhavar algumas perspectivas para os estudos organizacionais no Brasil.

i. Sobre a inter e multidisciplinaridade: a mesma depende e tem grande tendência a continuar a depender da iniciativa de poucos pesquisadores e grupos de pesquisa. Embora sejam pesquisadores e grupos promissores e competentes no avanço deste campo de estudos, os mesmos encontram

\footnotetext{
2 Ao mesmo tempo, muitas universidades praticamente condicionam qualquer apoio aos professores ao fato de terem ou não registro de grupo de pesquisa, o que pulveriza o número de grupos sem a necessária produção acadêmica, tendo relevância quantitativa nos processos de avaliação institucional sem a correspondente relevância científica.
} 
importantes obstáculos em seu fazer acadêmico: (a) a estrutura dos cursos de graduação e pós-graduação aos quais estes pesquisadores se vinculam é predominantemente disciplinar, dificultando a necessária interação das diversas áreas; (b) as agências de fomento, com destaque para o $\mathrm{CNPq}$, não abrigam uma área interdisciplinar, obrigando os pesquisadores e grupos a submeterem seus projetos à lista disciplinar oferecida, de forma que o julgamento dos projetos corre o risco de ser feito por avaliadores que nem sempre conseguem ter o alcance do significado da interdisciplinaridade; (iii) a interdisciplinaridade ainda é tratada com certo ceticismo e/ou desdém em alguns círculos acadêmicos, reproduzindo a lógica das corporações de ofício que caracteriza os conselhos de registro profissional; (iv) a iniciativa da criação da SBEO foi de pesquisadores da área da Administração, com poucos pesquisadores de outras áreas, o que vai exigir um esforço político, acadêmico e institucional de superação do vínculo dos EORs com a Administração, de forma a consolidar a SBEO como efetivamente uma sociedade de pesquisadores, desvinculada de estruturas disciplinares e de programas de graduação e pós-graduação; (v) a interdisciplinaridade não é um passaporte para que se utilizem conceitos de várias áreas (psicanálise, filosofia, direito, medicina, sociologia, etc.) de maneira rasa e irresponsável;

ii. Organização como objeto de pesquisa: esta é uma questão pacífica apenas aparentemente. Há uma discussão nos fóruns, por exemplo, sobre se Comportamento Organizacional pertence ou não à área de EOR. Trata-se de uma discussão, em meu ponto de vista, absolutamente irrelevante, a não ser por uma questão de poder político. Se comportamento organizacional estuda o comportamento das organizações ou o comportamento dos sujeitos na organização é também irrelevante. Estratégia organizacional não estuda o comportamento da organização? Relações de trabalho não estuda o comportamento dos sujeitos na organização? Relação de poder não estuda ambos? Poderíamos falar, do mesmo modo, do simbolismo, do imaginário, dos discursos, etc. É uma perda de tempo e energia prospectar as perspectivas da área de EOR a partir de discussões deste tipo. Estudos organizacionais são estudos realizados em organizações e/ou sobre organizações, ou seja, são estudos que têm as organizações como seu objeto, independentemente dos temas ou assuntos (gestão, poder, trabalho, comportamento, competência, 
simbolismo, etc.), desde que pertinentes, é óbvio. Mas aí habita, há tempos, um problema. O Estado é uma organização tanto quanto uma empresa, um órgão público, uma ONG, etc. Se tudo pode ser uma organização, temos uma hiperárea? Ou não temos nenhum objeto de fato? Para ter a organização como objeto, os EOR devem estudar o Estado, porém não como Estado; a empresa, todavia não como empresa; as ONGs, contudo não como ONGs, etc. Parece uma questão simples, mas a organização precisa ser estudada em sua materialidade e, portanto, nas suas formas manifestas e em suas essências. As perspectivas são promissoras, mas é necessário superar limitações epistemológicas e metodológicas, especialmente quanto ao empirismo, aos estudos de caso descontextualizados, às generalizações arbitrárias, aos modelos acabados, aos enquadramentos padronizados, ao raciocínio impermeável, etc. Finalmente, é preciso superar a escolha da organização pelo comodismo laborioso: o simbolismo no bar da esquina; as relações de poder na escola em que o pesquisador trabalha; a gestão por resultados no armazém do bairro; as relações de trabalho na construção do edifício na rua em que o pesquisador mora, etc.

iii. Xenofobia teórica: embora este assunto teime em voltar à tona, em uma referência equivocada à crítica de Guerreiro Ramos à importação de conceitos, este parece ser um elemento com poucas chances de prosperar. A utilização de teorias produzidas fora do Brasil tem sido muito cuidadosa por parte de pesquisadores de ponta, suplantando a mera reprodução. Mas o problema recorrente é que as reproduções existem. Então, aqui, as perspectivas são as de que é necessário exatamente superar o viés da importação objeto da crítica de Guerreiro Ramos, ou seja, a importação de modelos, conceitos, teorias, sistemas, sem rigor e de forma acrítica. Já não se trata de xenofobia, mas de cuidado com a apropriação inadequada e inconsistente de conceitos e teorias produzidas no mundo acadêmico, tratando-as como se fossem verdades absolutas e inquestionáveis, generalizáveis e aplicáveis em qualquer contexto sóciohistórico por justaposição;

iv. Grupos de pesquisa como feudos competitivos: este é um elemento que por certo provoca um furor basilar em certos pesquisadores e grupos, que atuam competitivamente no mundo acadêmico como se este fosse um mercado de financiamento, e/ou que disputam poder político e prestígio ritualístico e/ou que se deleitam na autovalorização de si. 
No discurso cobertura, todos são favoráveis à cooperação entre pesquisadores e grupos de pesquisa, mas há uma distância entre intenção e gesto, como diz Chico Buarque em Fado Tropical ${ }^{3}$. É fundamental reconhecer que a valorização da produção acadêmica de grupos e pesquisadores em EOR (como em outras tantas áreas), no Brasil, tem se apresentado historicamente como uma atividade imperialista de um eixo regional. O reconhecimento prático e histórico da produção fora do eixo é raro. Assim, não é incomum que alguns pesquisadores e grupos do eixo apresentem como sendo originalmente seus, estudos há tempos desenvolvidos em outros centros e que, por conta da visibilidade política da geografia institucionalizada, apropriem-se deles com ares de paternidade. Ao contrário de fazer avançar o campo do conhecimento em EOR, desenvolve-se um movimento de rotação acadêmica. Forma-se, assim, um círculo vicioso: pesquisadores do eixo que são avaliadores de projetos de fora do eixo; composição de conselhos acadêmicos predominantemente do eixo; valorização de periódicos no sistema Qualis com predomínio do eixo. Esta reprodução das condições de perpetuação do poder político na academia deixou de ser um mistério e se encontra exposta na mídia. Perspectivas? A SBEO poderá contrastar esta prática se definir como um de seus objetivos a democratização na distribuição de recursos de pesquisa, a valorização científica de grupos e de pesquisadores por sua produção, a promoção de isonomia na avaliação de periódicos tendo em vista seu impacto social e acadêmico.

Por fim, deixo aqui um desafio aos historiadores. Se todos desejam fazer da área de estudos organizacionais um campo de referência, é necessário resgatar sua verdadeira história. Do que tenho lido até o

\footnotetext{
3 "Meu coração tem um sereno jeito

E as minhas mãos o golpe duro e presto,

De tal maneira que, depois de feito,

Desencontrado, eu mesmo me contesto.

Se trago as mãos distantes do meu peito

É que há distância entre intenção e gesto

E se o meu coração nas mãos estreito,

Me assombra a súbita impressão de incesto.

Quando me encontro no calor da luta

Ostento a aguda empunhadura à proa,

Mas meu peito se desabotoa.

E se a sentença se anuncia bruta

Mais que depressa a mão cega executa,

Pois que senão o coração perdoa".
} 
momento, há omissões imperdoáveis de eventos, fatos históricos, produções originais, etc. Há desvalorizações inaceitáveis à boa prática acadêmica quanto à importância de pesquisadores na área e, ao mesmo tempo, marginalização inexplicável de pesquisadores que contribuíram decisivamente para o que a área é atualmente. Há distorções de fatos datados inadmissíveis, especialmente desconsideração de pesquisas relevantes (inclusive premiadas) e de desenvolvimento teórico pioneiro. $\mathrm{O}$ problema mais grave é que textos que buscam resgatar a "história dos EOR", ao promoverem estas distorções e omissões, estão formando uma falsa convicção da realidade histórica, que se vai reproduzindo de texto em texto, replicando as imperfeições, por conta de citações sem críticas e sem confronto com os fatos históricos, criando uma concepção que não é fiel aos acontecimentos, mas que passa a ser uma espécie de "história oficial", ou seja, uma história dos contadores de história que se contentam em narrar os eventos segundo suas convicções e interesses.

Pesquisadores, e historiadores em particular, precisam superar a prática um tanto cômoda de contar a história dos EOR tendo como única base de dados artigos publicados nos Anais do EnANPAD e em revistas clássicas (RAE, RAC, etc.) e garimpar fontes documentais mais amplas, buscando trabalhos publicados em revistas que nas décadas de 1970/1980 eram referência e que deixaram de ser veiculadas; encontrar livros em editoras de pequeno porte; fazer um levantamento exaustivo de cadernos e publicações patrocinadas por entidades governamentais, etc. Em resumo, fazer um estudo consistente para contar a mais fiel possível história dos EOR no Brasil. A realidade da publicação acadêmica nas décadas de 1970/1980 não tinha ainda, como parâmetro, a síndrome do Qualis Capes, que orienta o pensamento atual restringindo seu alcance. Assim, a história dos EOR foi reduzida a algumas (e, sem dúvida, muito importantes e, ouso dizer, fundamentais) contribuições, como as de Guerreiro Ramos e Maurício Tragtenberg. Contudo, há mais do que isto.

A história dos EOR no Brasil é maior do que a que é contada nos encontros, simpósios, fóruns, colóquios, congressos, etc. Maior do que o que registram periódicos que superaram as dificuldades financeiras e se mantiveram em atividade. Maior do que os dados disponíveis nos sites de acesso público (do tipo Google). Como pesquisador desde 1978 convivi com outros pesquisadores, estudei textos que por magia da memória curta das novas e velhas gerações desapareceram das citações como se nunca tivessem existido. Resultados de pesquisas e reflexões originais publicadas nas décadas de 1970/1980 têm sido solenemente ignorados e seus temas resurgem no final dos anos 1990 e nos anos 2000 como novidades (toyotismo, tecnologia e relações de trabalho, autogestão, gestão e subjetividade, para citar alguns exemplos), inclusive com a valorização de pesquisadores estrangeiros que chegaram aos temas anos após pesquisadores brasileiros o terem abordado. $\mathrm{O}$ colonizado parece sentir-se 
sempre devedor do colonizador, não importando sua origem, se francês, inglês, alemão, norte-americano ou brasileiro.

Maurício Tragtenberg deixou muitos ensinamentos aos seus discípulos (que ele se recusava a ter, mas que de fato tinha), como Fernando Coutinho Garcia, Fernando Prestes Motta, Antonio Valverde, Antonio Candido, Doris Accioly e Silva, Sonia Marrach, Evaldo Vieira, Lucia Bruno, Liliana Segnini, eu mesmo e muitos outros que partilhamos de sua orientação em longos debates, seminários e conversas de corredor. Um deles, no entanto, ficou gravado em minha memória e orientou minha vida acadêmica: "a crítica é uma das mais poderosas armas dos intelectuais revolucionários".

A crítica não tem compromisso com conluios, com restrições, com conveniências, com reações desconfortáveis, mas com os fatos. Pode ser certeira ou conter equívocos, que sempre podem ser corrigidos, mas deve ser expressa. Como disse Marx, citando Dante Alighieri em A Divina Comédia, no prefácio da primeira edição de O Capital: "segui il tuo corso, $e$ lascia dir le genti!" ("segue o teu curso e deixa a gentalha falar!"). Desta forma, permito-me, no próprio idioma italiano, concluir por mim mesmo que nella scienza, come nella vita, le cose devono avere il senso e il significato. Qualcosa che ha significato, ma non ha senso, quindi senza prospettive come qualcosa che rende il senso, ma che significa nulla (na ciência, como na vida, as coisas precisam ter sentido e significado. Algo que tenha significado, mas não faça sentido, é tão sem perspectivas como algo que faz sentido, mas que nada significa). 